\title{
The Relationship between Health Literacy and General Health Level of Hemodialysis Patients: A Case Study in Iran
}

\author{
Mohammadkarim Bahadori, ${ }^{1}$ Fahimeh Najari, ${ }^{2}$ and Khalil Alimohammadzadeh ${ }^{3,{ }^{*}}$ \\ ${ }^{1}$ Health Management Research Center, Baqiyatallah University of Medical Sciences, Tehran, Iran \\ ${ }^{2}$ Health Deputy, Bam University of Medical Sciences, Kerman, Iran \\ ${ }^{3}$ Department of Health Services Management, North Tehran Branch, Islamic Azad University, Tehran, Iran \\ "Corresponding author: Khalil Alimohammadzadeh, MD, PhD in Health Services Management, Associate Professor, Department of Health Services Management, North Tehran \\ Branch, Islamic Azad University, Tehran, Iran. Tel: +98-2122977862, E-mail: drkhalilalimohammadzadeh@gmail.com
}

Received 2018 February 27; Accepted 2018 April 24.

\begin{abstract}
Background: Health literacy includes the social cognitive skills that determine the motivation and ability of individuals in achieving, understanding, and utilizing information to maintain and enhance health. People with inadequate health literacy have a weaker health condition. The present study aimed at investigating the relationship between health literacy and the general health level of hemodialysis patients.

Methods: This descriptive - analytical study was performed on 130 hemodialysis patients of Baharlu Hospital in Tehran. Data were collected using Health Literacy and General Health Assessment Tool. The collected data were analyzed using SPSS 21.0 software and Spearman correlation test.

Results: The results revealed that the health literacy mean score was $46.81 \pm 22.87$ and that the studied individuals did not have sufficient health literacy. The general health mean score was $14.20 \pm 6.50$, and there was a statistically significant relationship between health literacy and general health $(\mathrm{P}<0.05)$.

Conclusions: In this study, it was found that those with higher health literacy score had better general health. Dialysis causes many clinical and psychological problems, limiting physical and mental activities of the patients. The decrease in health literacy is associated with a decrease in health including physical and psychological problems. In general, dialysis patients still need to learn more about health literacy and general health.
\end{abstract}

Keywords: Health Literacy, General Health, Dialysis

\section{Background}

The final stage of kidney failure is one of the major health problems in kidney patients (1). Chronic renal failure is the progressive and irreversible degeneration of renal performance, the main treatment of which is renal transplantation, and the patients must undergo dialysis while waiting for renal transplantation (2). The prevalence rate of chronic renal failure in the world is 242 cases per one million of the population, and this population annually increases by eight percent (3). In Iran, the prevalence and incidence of advanced renal failure in 2010 were, respectively, reported to be 357 and 57 cases per one million people over one year (4). Therefore, hemodialysis is the most common alternative treatment in the final stage of renal disease (5).

Nowadays, dialysis has succeeded in saving thousands of uremia patients from premature death. Dialysis units are presently available in all provinces and most cities of Iran; nevertheless, despite technical advancements in hemodialysis in the past ten years, the mortality rate of hemodialysis patients and the patients in the final stage of renal failure has remained high (6). In the United States and industrial countries, the annual mortality rate is $23 \%$ (7).

Due to the nature of their disease, hemodialysis patients experience many problems for undergoing hemodialysis including reduced self - confidence, social isolation, and lack of mobility, which will subsequently reduce patients' social interaction with others (8). The sense of inability, lack of control on the disease and treatment, financial problems, inability to maintain job, having multiple drug treatments, certain dietary plans, and having the ability to adapt to the physical and mental disabilities influence the quality of life of the patients undergoing dialysis (9).

Unfortunately, the social complications and psycho- 
logical pressure caused by hemodialysis in these patients reduce their general health and survival rates and increase their mortality rate. In a study in Singapore, survival rate was $89.3 \%$ in patients in their first year of hemodialysis but it decreased to $58.7 \%$ after five years (10). Hence, these patients face risk factors, such as early aging, physical and nutritional disability, heart failure, and depression. However, if patients actively control the disease and recognize its symptoms and complications, they can improve their health condition (11). One of the effective ways to decrease mortality rate and enhance the general health of these patients is to improve their health literacy level (12).

The costs of chronic diseases are exorbitant for the patient, the families, and the society. Chronic diseases can seriously disrupt the quality of health - related life of the people. Some of the demographic subgroups with financial deprivation and problems in health literacy level and language have been very vulnerable to receive desirable health care due to an unsuccessful relationship with physicians or an increase in care barriers. Global experiences suggest that such factors as economic development, enhancement of educational level, health literacy, and improving social services can have a positive influence on social health and welfare of the people in any society. The decrease in health literacy skills is a common issue in health care and is associated with adverse health outcomes (13).

Health literacy is a degree to which each individual has the necessary capacity to achieve, process, and understand the primary health information for appropriate health decision - making including a set of reading, listening, analyzing, and decision - making skills, and the ability to use these skills in health - related conditions that are not necessarily related to education years and general reading skills (14).

Health literacy has been introduced as a realistic approach for involving individuals in self - care and health enhancement activities (15). Low health literacy is associated with a high prevalence of chronic diseases and low general health (16). Unlike demographic features and social structures that are persistent and unchangeable without wide political and social activities, health literacy is modifiable and can be enhanced by health education (15).

Health literacy is associated with a wide range of health outcomes including adherence to proper drug use, participation in screening and health programs, self - care in chronic diseases, and other health recommendations (17). The results of recent researches indicate low health literacy in Iran $(18,19)$. Over the last few decades, general health has been known as an important health criterion and it has been believed that the results of health services not only increase life expectancy, but it should also improve the quality of life (20).
Studies have shown that people with higher health literacy have higher and more desirable performance in dealing with physical, psychological, and mental problems (21). On the other hand, renal diseases influence the general health of the patients and reduce their quality of life (22). For example, in their study on patients presenting to two large urban public hospitals in Atlanta, Baker et al. (1997) indicated that patients with inadequate functional health literacy were more likely to report their health as poor compared to patients with adequate literacy (23). Moreover, Omachi et al. (2009) concluded that regardless of the economic situation, low health literacy is associated with more intense disease, more severe shortness of breath, and lower quality of life (24).

Over the past 20 years, the interest in evaluating and improving the general health of patients with chronic diseases has significantly increased, so that improvement in daily performance and general health of the patients with chronic diseases has changed into a goal (25). Measuring general health in renal diseases is highly important, because although these diseases do not lead to a reduction in survival in many cases, they can influence the general health of people in various ways, such as itching and pain, mental stress, lack of self - confidence, confusion, impact on social and family relationships, treatment problems, financial burden, and waste of time (26).

\section{Objectives}

The present study aimed at investigating the relationship between health literacy and general health level of hemodialysis patients who referred to Baharlou hospital in Tehran.

\section{Methods}

In this descriptive - analytical study, we examined the relationship between health literacy and the general health of hemodialysis patients who referred to Baharlou hospital affiliated to Tehran University of Medical Sciences in 2017.

The study area included dialysis ward of Baharlou Hospital. Baharlou Hospital was established in the form of a small clinic in 1935 after the expansion of the railway network. It is now a general hospital that provides educational services for medical students in various levels. In addition, it provides treatment services with 330 approved beds and 258 active beds; it has emergency, pediatrics, obstetrics and gynecology, surgery, heart, CCU, ICU, neonates, dialysis, thalassemia, psychiatric, orthopedic, ENT, and poisoned (in two parts of poisoned and obstetrics and gyne- 
cology) wards. In the dialysis ward, 130 hemodialysis patients receive services three times a week on average. Due to the limited study society, sampling was not done, and all the study population was included in the study. Exclusion criteria were reluctance to participate in the study, psychological and mental problems, as well as the foreign citizenship of the patients.

Demographic features of the patients, such as age, sex, marital status, type of insurance, duration of hemodialysis, the frequency of dialysis per week, being affected by filed diseases (diabetes and blood pressure), employment status, economic status, and education level, were collected using a questionnaire.

Then, a shorter questionnaire of health literacy(HELIA) that seemed more applicable due to its shorter completion time (7 to 10 minutes) were used. This tool included 33 questions and investigated health literacy in the fields of availability (6 questions), reading skill (4 questions), understanding (7 questions), assessment (4 questions), and decision - making, and using health information (12 questions) (27). The patients were asked to respond to this questionnaire. The researcher referred to hemodialysis ward of Baharlou Hospital to collect data and started sampling after obtaining permissions and providing guidance from hospital's authorities.

Moreover, general health questionnaire (GHQ - 12), which was designed and developed by Goldberg and Hiller in 1979 and has four scales, was also used in this study (28). Scale A included physical symptoms such as feelings of the people about their health status, feeling of tiredness, and body symptoms. Scale B revealed anxiety symptoms, such as insomnia, and scale $C$ showed symptoms of social performance dysfunction, such as the ability of people in coping with the professional demands and daily life issues and their feelings about everyday life. In addition, scale D included depression symptoms, such as severe depression and a specific tendency to suicide. The time of performing this test was considered 2 minutes on average, and it investigated the disease symptoms and positive health status of the individual over the past one month (one month before implementing the test). To score this test, we used Likert scale ranking method (0-1-2-3). The score of each person in each area was between 0 and 9 and between 0 and 36 in total.

The validity and reliability of Health Literacy Questionnaire have been investigated in the study of Montazeri et al. Thus, its validity has been confirmed using qualitative and structural content method, its reliability has been confirmed by Cronbach's alpha method, and its alpha value has been reported to be 0.72 to 0.98 (27). In the study of Goldberg and Hiller, the internal consistency of this questionnaire was assessed by Cronbach's alpha coef- ficient and found to be 0.80 . The reliability of the questionnaire was also investigated by an analytical method of known groups.

The researcher distributed the questionnaires among the patients. After completion, the questionnaires were coded and entered into the software to be analyzed. This study was performed from April to July 2017.

Data were analyzed using SPSS Version 21 software. Descriptive statistics (mean, standard deviation, percentage, and frequency) were also used. Spearman's correlation test was used to investigate the relationship between health literacy and general health. Kolmogorov - Smirnov test was used to investigate the normality of the variables. Significance level for all variables was less than 0.05. Data distribution was not normal, and thus non - parametric tests were used.

\subsection{Ethical Considerations}

Ethical considerations were as follow: obtaining an ethical code from the Ethics Committee of the University; obtaining the introduction letter from the faculty and presenting it to the hospital; obtaining the consent of patients before performing the study; respecting the patients at the time of performing the study; ensuring the privacy of patients' information; and optional participation of the patients in the study.

\section{Results}

From 130 studied patients, 63.1\% were male, and 83.1\% of the patients were married. Most of patients were more than 60 years old (50.8\%), unemployed (49.2\%), and illiterate $(47.7 \%)$. With respect to the variable of dialysis initiation time, the initial dialysis time for $60 \%$ of the patients was three years ago, it was between three to five years for $12.3 \%$ of the patients, and for the rest of the patients, it was more than five years. About supportive resources, $83.8 \%$ were supported by insurance, $13.1 \%$ by the Association for Supporting Kidney Patients, and the rest were supported by Relief Committee. About being affected by other diseases, $73.8 \%$ suffered from other diseases and $26.2 \%$ were only dialyzed and did not suffer from other diseases.

The total health literacy score for the patients was obtained to be 46.81 . Also, among the variables, decision making and using health information obtained the highest mean with the score of 57.24.

The results revealed that health literacy of $53.8 \%$ of the patients was insufficient, $26.2 \%$ of them were not educated enough, $13.8 \%$ had adequate literacy, and 6.2\% had excellent literacy.

Regarding the investigation of the general health status, the results showed that only $10.8 \%$ of the patients had 


\begin{tabular}{|c|c|c|}
\hline Variable & Frequency & Percentage \\
\hline \multicolumn{3}{|l|}{ Age, $y$} \\
\hline $30-40$ & 14 & 10.8 \\
\hline $41-50$ & 22 & 16.9 \\
\hline $51-60$ & 28 & 21.5 \\
\hline Over 60 & 66 & 50.8 \\
\hline \multicolumn{3}{|l|}{ Marital status } \\
\hline Married & 108 & 83.1 \\
\hline Single & 22 & 16.9 \\
\hline \multicolumn{3}{|l|}{ Job status } \\
\hline Employed & 5 & 3.8 \\
\hline Retired & 61 & 46.9 \\
\hline Unemployed & 64 & 49.2 \\
\hline \multicolumn{3}{|l|}{ Gender } \\
\hline Male & 82 & 63.1 \\
\hline Female & 48 & 36.9 \\
\hline \multicolumn{3}{|l|}{ Education } \\
\hline Illiterate & 62 & 47.7 \\
\hline Reading and writing & 50 & 38.5 \\
\hline Guidance school and diploma & 14 & 10.8 \\
\hline Higher education & 4 & 3.1 \\
\hline \multicolumn{3}{|l|}{ Dialysis initiation time } \\
\hline One to three years & 78 & 60 \\
\hline Three to five years & 16 & 12.3 \\
\hline More than five years & 36 & 27.7 \\
\hline \multicolumn{3}{|l|}{ Supportive resources } \\
\hline Insurance & 109 & 83.8 \\
\hline $\begin{array}{l}\text { The Association for Supporting Kidney } \\
\text { Patients }\end{array}$ & 17 & 13.1 \\
\hline Relief Committee & 4 & 3.1 \\
\hline \multicolumn{3}{|l|}{ Being affected by other diseases } \\
\hline Yes & 96 & 73.8 \\
\hline No & 34 & 26.2 \\
\hline Total & 130 & 100 \\
\hline
\end{tabular}

not experienced any problems, $66.2 \%$ had mild problems, and $16.9 \%$ had moderate problems. In addition, $6.2 \%$ of the patients had severe problems.

With respect to the investigation of the relationship between general health and health literacy and its aspects, the results revealed a significant and inverse relationship among understanding aspects, assessment, and decision making and using information with the general health of

\begin{tabular}{|c|c|c|c|}
\hline Aspects & & $\begin{array}{l}\text { Mean (of } \\
\text { 100) }\end{array}$ & $\begin{array}{l}\text { Standard } \\
\text { Deviation }\end{array}$ \\
\hline Availability & & 40.38 & 26.13 \\
\hline Reading skill & & 47.59 & 23.59 \\
\hline Understanding & & 50.98 & 31.1 \\
\hline Assessment & & 37.88 & 26.29 \\
\hline $\begin{array}{l}\text { Decision - making and using health } \\
\text { information }\end{array}$ & & 57.24 & 26.21 \\
\hline Total health literacy & & 46.81 & 22.87 \\
\hline \multicolumn{4}{|c|}{ rable 3. Description of Patients' Status in Health Literacy Component } \\
\hline Status & $\begin{array}{c}\text { Range of } \\
\text { Scores }\end{array}$ & Frequency & Percentage \\
\hline Insufficient literacy & $0-50$ & 70 & 53.8 \\
\hline Not enough health literacy & $50.1-66$ & 34 & 26.2 \\
\hline Adequate health literacy & $66.1-84$ & 18 & 13.8 \\
\hline Excellent health literacy & $84.1-100$ & 8 & 6.2 \\
\hline Total health literacy & $0-100$ & 130 & 100 \\
\hline \multicolumn{4}{|c|}{ Table 4. Description of the Patients' Status in the General Health Component } \\
\hline Problem's status & $\begin{array}{l}\text { Range of } \\
\text { scores }\end{array}$ & Frequency & Percentage \\
\hline None or minimum & $0-9$ & 14 & 10.8 \\
\hline Mild & $10-18$ & 86 & 66.2 \\
\hline Average & $19-24$ & 22 & 16.9 \\
\hline Severe & $28-36$ & 8 & 6.2 \\
\hline Total & 0.36 & 130 & 100 \\
\hline
\end{tabular}

patients $(\mathrm{P}<0.05)$.

\section{Discussion}

The results revealed that the health literacy of $53.8 \%$ of the patients was insufficient, $26.2 \%$ did not have enough health literacy, $13.8 \%$ had adequate literacy, and $6.2 \%$ had excellent literacy. In the research of Karimi et al. (2014)(29), it was revealed that health literacy is the average or boundary, which is consistent with the results of the current study. National assessment of adults' literacy in the United States in 2003 indicated that $36 \%$ of adults did not have adequate health literacy (30). Moreover, Williams (2002) (31) showed that health literacy level in the studied patients was very inadequate, which is consistent with the findings of the current study. However, there were other studies inconsistent with the results of this study. The results of the study of Tal (2012) on women who referred to Tehran University of Medical Sciences showed that the information lit- 


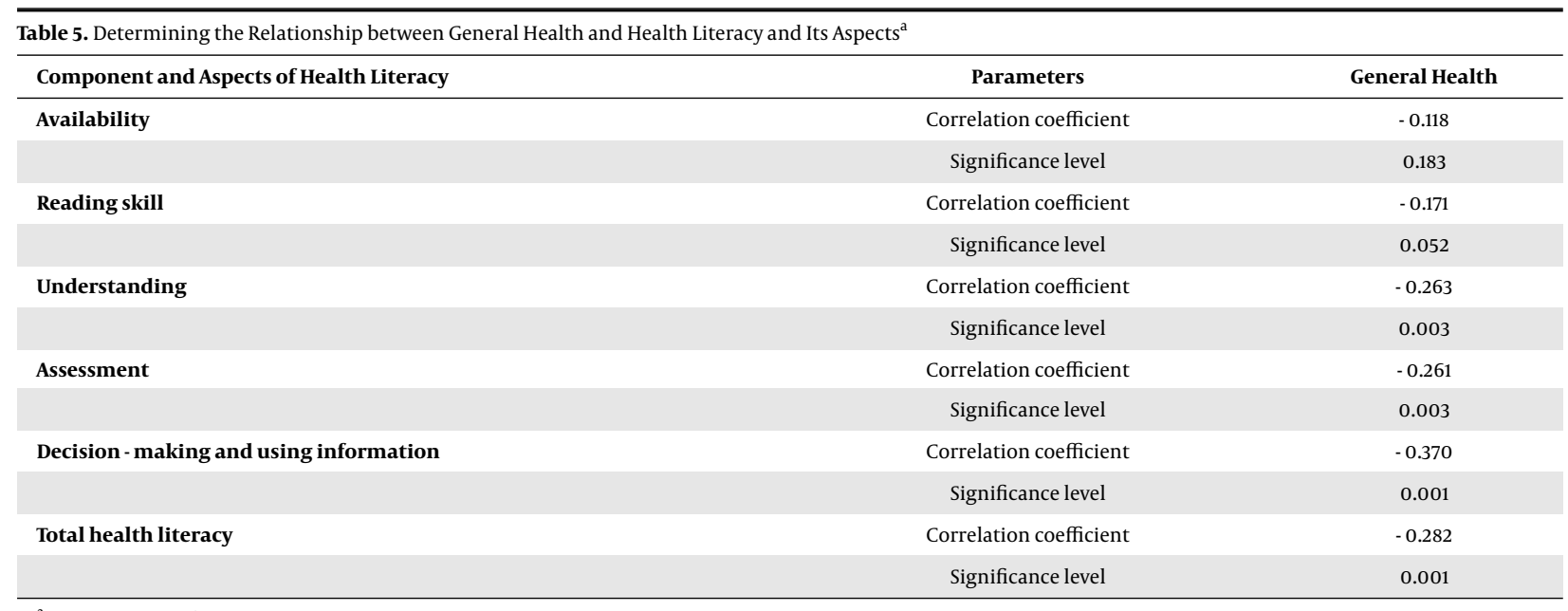

${ }^{\mathrm{a}}$ Spearman Correlation Test.

eracy of more than $80 \%$ of them was adequate, which was inconsistent with the results of the current study. This difference may be due to the type of the studied patients because the studied patients in the current study were dialysis patients who often have lower education level and social status that could influence their informational literacy.

Considering the total average for informational literacy, the results also indicated that the total average obtained for the health literacy score was 46.81 , and this average value is in the range of insufficient and inadequate health literacy. In the study of Rafi' Zadeh in 2014 that was performed on the patients of the city of Gorgan, the average health literacy was found to be $86.7 \%$, which was not consistent with the current study. The results of the study of MacLeod et al. (32) revealed that among the respondents, $23 \%$ and $16 \%$ of sicker and healthier patients, indicated inadequate HL, respectively.

As health literacy is a global issue and according to the World Health Organization (WHO), it plays a pivotal role in determining health inequalities whether in rich or poor countries (33), thus increasing knowledge and literacy of the patients is highly important in their improvement process. Health literacy is a concept that describes the ability of the patient to understand the information and the resources offered by physicians and experts (34), and it includes a range of simple and complex skills allowing the individuals to participate in treatment decision - makings and protect themselves, their families, and their society against diseases (35).

In general, this study indicated that the health literacy of patients is insufficient, as about $60 \%$ of them had inadequate health literacy. Thus, necessary steps should be taken to improve the health literacy level of the soci- ety. All parts of the society including mass media should try to enhance the health literacy of all people in the society by preparing health information plans appropriate to the requirements and ability of the audience. Moreover, they should help enhance health literacy level by creating simple and understandable educational media for people with low health literacy. In addition, experts in the health profession should prepare educational resources, such as websites and audiovisual materials, and brochures, to increase the public's health litracy. It is expected that with improving the health literacy level of the people, the problems caused by inadequate health literacy be reduced.

Regarding the investigation of the general health status, the results showed that only $10.8 \%$ of patients had not experienced any problem, $66.2 \%$ had mild problems, $16.9 \%$ had moderate problems, and $6.2 \%$ had severe problems. Several studies investigated the psychological health of the people in Iran and other countries, which had differences and similarities to the current study in aspects of psychological health. In this regard, in his study, Mostafa Zadeh indicated that $94.73 \%$ of the studied samples had an average level of psychological health (36). The status of general health average score obtained in this study was higher than that of the study performed by Calnan et al. in England (37), which is consistent with the current study.

The inconsistency in the number and volume of samples, heterogeneity of sectors, and type of diseases can be considered as possible causes of this difference. Nevertheless, in all presented studies within and out of the country and in the current study, the rate of suspected cases of psychological disorders was higher than the general population. Information obtained in this field indicates that the suspected cases of psychological disorders in the general population in another country have been different 
from $21.67 \%$ to $24.5 \%(38,39)$. The most important possible causes of higher prevalence rate of psychological health disorder in dialysis patients may be the stressful nature of this disease, exposure to unexpected situations, as well as individual factors.

The results of this study revealed a significant and inverse relationship between $t$ health literacy and general health, indicating that with the increase in health literacy scores, the problems of patients in general health and its aspects decreased. This significant relationship has been reported in many studies. In the study of Macabasco et al. (2011), a significant statistical relationship was found between health literacy and general health of the patients, and similar to the present study, the patients with adequate health literacy had a higher quality of life (40). The results of the present study are consistent with those of the study of Song et al. (2012) who investigated the relationship between health literacy and quality of life relevant to the health of patients (41).

In the study of Wolf et al. (2005), the patients with insufficient health literacy level significantly reported lower average physical and psychological health (42). Also, in another study, it was found that the patients with higher health literacy level were more informed about their health status. In general, there is a direct relationship between health literacy and health status (43). A study was performed on Japanese adults and found that weak health literacy is associated with weak physical and psychological health status (44) because inadequate health literacy severely influences the knowledge of patients, self - care, health status, and hospitalization risks (45).

Regarding the limitations of the study, since the patients did not have good physical and psychological status before hemodialysis and at the beginning of hemodialysis due to the accumulation of toxins in their bodies, the questionnaire was completed within the last 30 minutes of hemodialysis or after completion of hemodialysis.

\subsection{Conclusions}

Health literacy significantly influences the different aspects of the general health of the patients. Thus, to increase the health literacy level of the people in the society, not only using approaches like simplifying the information and employing simple and understandable educational materials can be helpful, but also using communicative approaches and the help of health education experts would be useful in planning and designing helpful educational plans. Moreover, by considering the level of abilities and skills of the individuals, we can select the best educational approaches and take an effective step to develop the health literacy skills in the society. All parts of the society including mass media should be involved in developing the health literacy of individuals through providing health information plans appropriate to the needs and abilities of the audience. In addition, the experts in the health profession should prepare educational resources (including websites and audiovisual materials, brochures, or other forms of resources) to increase the health literacy of the general population.

\section{Acknowledgments}

We thank participants and partners for their kind cooperation in this study. The present article was extracted from the thesis of a MSc student of Islamic Azad University.

\section{Footnotes}

Authors' Contribution: Mohammadkarim Bahadori and Khalil Alimohammadzadeh conducted the study concept and designed and developed the methods. Fahimeh Najari collected and interpreted the data. Mohammadkarim Bahador and Fahimeh Najari wrote the primary draft of the manuscript. All the authors contributed to the revision of the manuscript, and read and approved the final version.

Financial Disclosure: No benefits in any form were received or would be received from a commercial party related directly or indirectly to the subject of this manuscript.

Funding/Support: The authors declare no funding.

\section{References}

1. Kaba E, Bellou P, Iordanou P, Andrea S, Kyritsi E, Gerogianni G et al. Problems experienced by haemodialysis patients in Greece. Br J Nurs. 2007;16(14):868-72. doi: 10.12968/bjon.2007.16.14.24325. [PubMed: 17851348].

2. Heidarzadeh M, Atashpeikar S, Jalilazar T. Relationship between quality of life and self-care ability in patients receiving hemodialysis. Iran J Nurs Midwifery Res. 2010;15(2):71-6. [PubMed: 21589783]. [PubMed Central: PMC3093176].

3. Xue JL, Ma JZ, Louis TA, Collins AJ. Forecast of the number of patients with end-stage renal disease in the United States to the year 2010. JAm Soc Nephrol. 2001;12(12):2753-8. [PubMed: 11729245].

4. Hassanzadeh J, Hashiani AA, Rajaeefard A, Salahi H, Khedmati E, Kakaei $\mathrm{F}$, et al. Long-term survival of living donor renal transplants: A single center study. Indian J Nephrol. 2010;20(4):179-84 doi: 10.4103/0971-4065.73439. [PubMed: 21206678]. [PubMed Central: PMC3008945].

5. Thorsteinsdottir B, Swetz KM, Feely MA, Mueller PS, Williams AW. Are there alternatives to hemodialysis for the elderly patient with end-stage renal failure? Mayo Clin Proc. 2012;87(6):514-6. doi: 10.1016/j.mayocp.2012.02.016. [PubMed: 22677071]. [PubMed Central: PMC3498386].

6. Hakim RM, Depner TA, Parker TF. Adequacy of Hemodialysis. Am J Kidney Dis. 1992;20(2):107-23. doi: 10.1016/s0272-6386(12)80538-5. 
7. Sehgal AR, Leon JB, Siminoff LA, Singer ME, Bunosky LM, Cebul RD. Improving the quality of hemodialysis treatment: a community-based randomized controlled trial to overcome patient-specific barriers. JAMA. 2002;287(15):1961-7. [PubMed: 11960538].

8. Kazemi M, Nasrabadi AN, Hasanpour M, Hassankhani H, Mills J. Experience of Iranian persons receiving hemodialysis: a descriptive, exploratory study. Nurs Health Sci. 2011;13(1):88-93. doi: 10.1111/j.14422018.2011.00586.x. [PubMed: 21426460].

9. Tsay SL, Hung LO. Empowerment of patients with end-stage renal disease-a randomized controlled trial. Int J Nurs Stud. 2004;41(1):5965. [PubMed: 14670395].

10. Joshi VD, Mooppil N, Lim JF. Validation of the kidney disease quality of life-short form: a cross-sectional study of a dialysis-targeted health measure in Singapore. BMC Nephrol. 2010;11:36. doi: 10.1186/1471-236911-36. [PubMed: 21172008]. [PubMed Central: PMC3014913].

11. Welch JL, Austin JK. Stressors, coping and depression in haemodialysis patients. J Adv Nurs. 2001;33(2):200-7. [PubMed: 11168703].

12. Griva K, Mooppil N, Seet P, Krishnan DS, James H, Newman SP. The NKF-NUS hemodialysis trial protocol - a randomized controlled trial to determine the effectiveness of a self management intervention for hemodialysis patients. BMC Nephrol. 2011;12:4. doi: 10.1186/1471-236912-4. [PubMed: 21272382]. [PubMed Central: PMC3048524].

13. Kandula NR, Nsiah-Kumi PA, Makoul G, Sager J, Zei CP, Glass S, et al. The relationship between health literacy and knowledge improvement after a multimedia type 2 diabetes education program. Patient Educ Couns. 2009;75(3):321-7. doi:10.1016/j.pec.2009.04.001. [PubMed: 19395223].

14. McCray AT. Promoting health literacy. J Am Med Inform Assoc. 2005;12(2):152-63. doi: 10.1197/jamia.M1687. [PubMed: 15561782]. [PubMed Central: PMC551547].

15. Saha S. Improving literacy as a means to reducing health disparities.J Gen Intern Med. 2006;21(8):893-5. doi:10.1111/j.1525-1497.2006.00546.x. [PubMed: 16881955]. [PubMed Central: PMC1831565].

16. Curtis LM, Wolf MS, Weiss KB, Grammer LC. The impact of health literacy and socioeconomic status on asthma disparities. J Asthma. 2012;49(2):178-83. doi: 10.3109/02770903.2011.648297. [PubMed: 22277072]. [PubMed Central: PMC3509174].

17. Baker DW, Wolf MS, Feinglass J, Thompson JA, Gazmararian JA, Huang J. Health literacy and mortality among elderly persons. Arch Intern Med. 2007;167(14):1503-9. doi: 10.1001/archinte.167.14.1503. [PubMed: 17646604].

18. Haghdoost AA, Rakhshani F, Aarabi M, Montazeri A, Tavousi M, Solimanian A, et al. Iranian Health Literacy Questionnaire (IHLQ): An Instrument for Measuring Health Literacy in Iran. Iran Red Crescent Med J. 2015;17(6). e25831. doi: 10.5812/ircmj.17(5)2015.25831. [PubMed: 26290752]. [PubMed Central: PMC4537788].

19. Mollakhalili H, Papi A, Zare-Farashbandi F, Sharifirad G, HasanZadeh A. A survey on health literacy of inpatient's educational hospitals of Isfahan University of Medical Sciences in 2012. J Educ Health Promot. 2014;3:66. doi: 10.4103/2277-9531.134804. [PubMed: 25077159]. [PubMed Central: PMC4113979].

20. Pamuk ER, Wagener DK, Molla MT. Achieving national health objectives: the impact on life expectancy and on healthy life expectancy. Am J Public Health. 2004;94(3):378-83. [PubMed: 14998799]. [PubMed Central: PMC1448261]

21. Wickstead R, Furnham A. Comparing mental health literacy and physical health literacy: an exploratory study. J Ment Health. 2017;26(5):449-56. doi: 10.1080/09638237.2017.1294743. [PubMed: 28290733]

22. Pagels AA, Soderkvist BK, Medin C, Hylander B, Heiwe S. Health-related quality of life in different stages of chronic kidney disease and at initiation of dialysis treatment. Health Qual Life Outcomes. 2012;10:71. doi: 10.1186/1477-7525-10-71. [PubMed: 22710013]. [PubMed Central: PMC3511211].

23. Baker DW, Parker RM, Williams MV, Clark WS, Nurss J. The relationship of patient reading ability to self-reported health and use of health services. Am J Public Health. 1997;87(6):1027-30. [PubMed: 9224190]. [PubMed Central: PMC1380944].

24. Omachi TA, Sarkar U, Yelin EH, Blanc PD, Katz PP. Lower health literacy is associated with poorer health status and outcomes in chronic obstructive pulmonary disease. J Gen Intern Med. 2013;28(1):74-81. doi: 10.1007/s11606-012-2177-3. [PubMed: 22890622]. [PubMed Central: PMC3539035].

25. Sammarco A. Perceived social support, uncertainty, and quality of life of younger breast cancer survivors. Cancer Nurs. 2001;24(3):212-9. [PubMed: 11409065].

26. Cestari TF, Hexsel D, Viegas ML, Azulay L, Hassun K, Almeida AR, et al. Validation of a melasma quality of life questionnaire for Brazilian Portuguese language: the MelasQoL-BP study and improvement of QoL of melasma patients after triple combination therapy. Br J Dermatol. 2006;156 Suppl 1:13-20. doi: 10.1111/j.1365-2133.2006.07591.x. [PubMed: 17176300].

27. Montazeri A, Tavousi M, Rakhshani F, Azin SA, Jahangiri K, Ebadi M, et al. Health Literacy for Iranian Adults (HELIA): development and psychometric properties. Payesh. 2014;13(1):589-99. Persian.

28. Goldberg DP, Hillier VF. A scaled version of the General Health Questionnaire. Psychol Med.2009;9(1):139. doi:10.1017/s0033291700021644.

29. Karimi S, Keyvanara M, Hosseini M, Jazi MJ, Khorasani E. The relationship between health literacy with health status and healthcare utilization in 18-64 years old people in Isfahan. J Educ Health Promot. 2014;3:75. doi: 10.4103/2277-9531.134910. [PubMed: 25077168]. [PubMed Central: PMC4113988].

30. Muir KW, Lee PP. Health literacy and ophthalmic patient education. Surv Ophthalmol. 2010;55(5):454-9. doi: 10.1016/j.survophthal.2010.03.005. [PubMed: 20650503]. [PubMed Central: PMC2918723].

31. Williams MV. Recognizing and overcoming inadequate health literacy, a barrier to care. Cleve Clin J Med. 2002;69(5):415-8. [PubMed: 12022385].

32. MacLeod S, Musich S, Gulyas S, Cheng Y, Tkatch R, Cempellin D, et al. The impact of inadequate health literacy on patient satisfaction, healthcare utilization, and expenditures among older adults. Geriatr Nurs. 2017;38(4):334-41. doi: 10.1016/j.gerinurse.2016.12.003. [PubMed: 28089217].

33. Al Sayah F, Majumdar SR, Egede LE, Johnson JA. Associations between health literacy and health outcomes in a predominantly low-income african american population with type 2 diabetes. $J$ Health Commun. 2015;20(5):581-8. doi: 10.1080/10810730.2015.1012235. [PubMed: 25826448].

34. Noblin AM, Wan TT, Fottler M. The impact of health literacy on a patient's decision to adopt a personal health record. Perspect Health Inf Manag. 2012;9:1-13. [PubMed: 23209454]. [PubMed Central: PMC3510648].

35. Zarcadoolas C, Pleasant A, Greer DS. Understanding health literacy: an expanded model. Health Promot Int. 2005;20(2):195-203. doi: 10.1093/heapro/dah609. [PubMed: 15788526].

36. Mostafazadeh F, Asadzadeh F. Spiritual health of midwifery students. J Health Care. 2012;14(1):19-23. Persian.

37. Calnan M, Wainwright D, Forsythe M, Wall B, Almond S. Mental health and stress in the workplace: the case of general practice in the UK. Soc Sci Med. 2001;52(4):499-507. [PubMed: 11206648].

38. Arafa MA, Nazel MW, Ibrahim NK, Attia A. Predictors of psychological well-being of nurses in Alexandria, Egypt. Int J Nurs Pract. 2003;9(5):313-20. [PubMed: 14531854].

39. Yang MS, Pan SM, Yang MJ. Job strain and minor psychiatric morbidity among hospital nurses in southern Taiwan. Psychiatry Clin Neurosci.2004;58(6):636-41. doi: 10.1111/j.1440-1819.2004.01314.x. [PubMed: 15601389].

40. Macabasco-O'Connell A, DeWalt DA, Broucksou KA, Hawk V, Baker DW, Schillinger D, et al. Relationship between literacy, knowledge, self-care behaviors, and heart failure-related quality of life among 
patients with heart failure. $J$ Gen Intern Med. 2011;26(9):979-86. doi: 10.1007/s11606-011-1668-y. [PubMed: 21369770]. [PubMed Central: PMC3157534].

41. Song L, Mishel M, Bensen JT, Chen RC, Knafl GJ, Blackard B, et al. How does health literacy affect quality of life among men with newly diagnosed clinically localized prostate cancer? Findings from the North Carolina-Louisiana Prostate Cancer Project (PCaP). Cancer. 2012;118(15):3842-51. doi: 10.1002/cncr.26713. [PubMed: 22180041].

42. Wolf MS, Gazmararian JA, Baker DW. Health literacy and functional health status among older adults. Arch Intern Med. 2005;165(17):194652. doi: 10.1001/archinte.165.17.1946. [PubMed: 16186463].

43. Walker J, Pepa C, Gerard PS. Assessing the health literacy levels of pa- tients using selected hospital services. Clin Nurse Spec. 2010;24(1):31-7. doi: 10.1097/NUR.ob013e3181c4abdo. [PubMed: 20010182].

44. Tokuda Y, Doba N, Butler JP, Paasche-Orlow MK. Health literacy and physical and psychological wellbeing in Japanese adults. Patient Educ Couns. 2009;75(3):411-7. doi: 10.1016/j.pec.2009.03.031. [PubMed: 19403259].

45. Baker DW, Gazmararian JA, Williams MV, Scott T, Parker RM, Green $\mathrm{D}$, et al. Functional health literacy and the risk of hospital admission among Medicare managed care enrollees. Am J Public Health. 2002;92(8):1278-83. [PubMed: 12144984]. [PubMed Central: PMC1447230]. 